Supporting Information

\title{
Biocompatible Micropatterning of Two Different Cell Types
}

\author{
Carlos C. Co, Yu-Chi Wang, Chia-Chi Ho * \\ University of Cincinnati, Department of Chemical and Materials Engineering, 497 Rhodes \\ Hall, Cincinnati, $\mathrm{OH} 45221$
}

*Corresponding author. E-mail: cho@alpha.che.uc.edu

\section{Experimental Methods}

Preparation of poly(OEGMA-co-MA). Random copolymers of OEGMA and MA (Scientific Polymer Products, NY) were prepared by free radical polymerization of the respective monomers in methanol at $60^{\circ} \mathrm{C}$. Polymerization, starting with $10 \mathrm{wt} \%$ monomer in methanol with an 80:20 mass ratio of OEGMA:MA was initiated with $1 \mathrm{wt} \%$ 2,2'-azobis(2-amidinopropane) dihydrochloride (Wako, VA) and allowed to react for 16 hours. The optimal OEGMA:MA mass ratio of 80:20 for patterning endothelial cells on chitosan substrates was determined in a previous study. ${ }^{1}$

Fabrication of chitosan and gelatin films. Chitosan films were prepared on glass slides by spreading uniformly $2.5 \%$ chitosan solutions in $0.2 \mathrm{M}$ acetic acid. The wet films were dried in an oven at $56^{\circ} \mathrm{C}$ for 30 minutes then neutralized with $2 \mathrm{~N} \mathrm{NaOH}$ and soaked in deionized water overnight. Gelatin films were prepared by casting $8 \%$ gelatin (Sigma Cat\# G2500) solutions in $0.2 \mathrm{M}$ acetic acid on a glass slide. After drying, the gelatin films were removed from the glass slides, crosslinked with $0.5 \%$ glutaraldehyde 
solution, rinsed with deionized water, and air dried. Before use in cell cultures, both chitosan and gelatin films were sterilized in $70 \%$ ethanol solution, rinsed, and immersed in Hank's buffered saline solution (HBSS, Life Technologies).

Fabrication of micropatterned substrates. Micropatterns with parallel grooves $60 \mu \mathrm{m}$ wide and ridges $20 \mu \mathrm{m}$ in width were fabricated on silicon wafers using standard photolithographic techniques. From this silicon master pattern, complementary polydimethylsiloxane (PDMS) replicas were formed by pouring PDMS prepolymer (mixed in a 10:1 ratio with a cross linking catalyst) over the Si master and cured at $56^{\circ} \mathrm{C}$ for 2 hours. The PDMS replicas with line patterns on its surface was inked with $10 \%$ poly(OEGMA-co-MA) and air dried. The inked stamp was then brought into contact with the substrate for 3 seconds then peeled away.

Co-culture of endothelial cells and fibroblasts. Human microvascular endothelial cells (HMVEC-d, purchased from Cambrex biosciences, MD) were cultured in endothelial basal medium (EBM) containing $5 \%$ fetal bovine serum, $1 \mu \mathrm{g} / \mathrm{ml}$ hydrocortisone, $10 \mu \mathrm{g} / \mathrm{ml}$ epidermal growth factor (EGF), $10 \mu \mathrm{g} / \mathrm{ml}$ bovine brain extract, $50 \mu \mathrm{g} / \mathrm{ml}$ gentamycin, and $50 \mu \mathrm{g} / \mathrm{ml}$ amphotericin-B, under $5 \% \mathrm{CO}_{2}$. NIH 3T3 fibroblasts, kindly provided by W. Ip (University of Cincinnati), were cultured in Dulbecco's modified eagle medium (DMEM) supplemented with $10 \%$ fetal bovine serum, glutamine $(0.3 \mathrm{mg} / \mathrm{mol})$, penicillin $(100 \mathrm{U} / \mathrm{mL})$, streptomycin $(100 \mu \mathrm{g} / \mathrm{mL})$, $20 \mathrm{mM} \mathrm{N}$-2-hydroxyethylpiperzine- $N$ '-2-ethanesulfonic acid (HEPES), and D-glucose $(5 \mu \mathrm{g} / \mathrm{L})$.

For patterned monolayers of endothelial cells and fibroblasts (Figures 2a-c) where no capillary tube-like structures were formed, endothelial cells were incubated with Cell 
Tracker Green (Molecular Probes, Inc., Eugene, OR) for 30 minutes, rinsed, dissociated from the culture dish with trypsin, then resuspended in EBM containing 10\% serum at a concentration of $10^{4}$ cells $/ \mathrm{ml}$. The endothelial cells were plated onto micropatterned chitosan substrates and allowed to attach and proliferate to fill the $20 \mu \mathrm{m}$ wide lines of bare chitosan. Following 3 days in culture, the substrate along with the attached cells are immersed into EBM medium containing 1\% chitosan (182 kDaltons, 69\% deacetylation, TRI Corporation, Alpharetta, GA) for 30 minutes to switch the cell resistant regions on the substrate through adsorption of cell adhesive chitosan. The chitosan coating on poly(OEGMA-co-MA) under these conditions was approximately $100 \mathrm{~nm}$ thick (AFM). After washing with PBS, the medium was replaced with EBM containing 10\% serum and fibroblasts labelled with Cell Tracker Orange (Molecular Probes, Inc., Eugene, OR) at a concentration of $10^{4}$ cells $/ \mathrm{mL}$. Co-cultures containing HMVEC and fibroblasts were maintained in HMVEC medium at $37^{\circ} \mathrm{C}$ for 12 hours then examined by fluorescence microscopy.

Endothelial cells cultured on $20 \mu \mathrm{m}$ wide lines of chitosan remained as monolayers and do not form capillary tube-likes structures even after 7 days in culture. Endothelial cells on $20 \mu \mathrm{m}$ wide line patterned gelatin substrates, however, do differentiate to form capillary tube-like structures (Figures 2d-e) after 5 days. In this case, the endothelial cells that formed the capillary tube-like structures were stained with Cell Tracker Green ( $1 \mu \mathrm{M}$, Molecular Probes, Inc., Eugene, OR) for 30 minutes. The substrate with the capillary tube-like structures is subsequently immersed in chitosan solution and seeded with fibroblasts labelled with Cell Tracker Orange following the procedure described above. A higher seeding density $\left(10^{5}\right.$ cells $\left./ \mathrm{mL}\right)$ of fibroblasts was used which led to full coverage of both the previously cell-resistant line patterns, and the capillary tube-like structures (Figure 2f). 
Immunofluorescence images were obtained with Nikon TE-2000 inverted microscope and Zeiss LSM 510 laser scanning confocal microscope.

(1) Kumar, G.; Wang, Y.; Co, C.; Ho, C. Langmuir 2003, 19, 10550-10556. 